\title{
Altered Expression of MBNL Family of Alternative Splicing Factors in Colorectal Cancer
}

\author{
NAZILA NAVVABI ${ }^{1}$, PAVLA KOLIKOVA $^{1}$, PETR HOSEK $^{1}$, FRANTISEK ZITRICKY $^{1}$, \\ AZITA NAVVABI $^{2}$, ONDREJ VYCITAL ${ }^{1,3}$, JAN BRUHA $^{1,3}$, RICHARD PALEK $^{1,3}$, \\ JACHYM ROSENDORF ${ }^{1,3}$, VACLAV LISKA ${ }^{1,3}$ and PAVEL PITULE ${ }^{1,4}$ \\ ${ }^{1}$ Biomedical Center, Faculty of Medicine in Pilsen, Charles University, Pilsen, Czech Republic; \\ ${ }^{2}$ Biological Center, Faculty of Marine Sciences and Technologies in Bandar Abbas, \\ Hormozgan University, Hormozgan, Iran; \\ ${ }^{3}$ Department of Surgery, Faculty of Medicine in Pilsen, Charles University, Pilsen, Czech Republic; \\ ${ }^{4}$ Department of Histology and Embryology, Faculty of Medicine in Pilsen, \\ Charles University, Pilsen, Czech Republic
}

\begin{abstract}
Background/Aim: Colorectal cancer is currently the third leading cause of cancer-related deaths and recently, alternative splicing has risen as its important regulator and potential treatment target. In the present study, we analyzed gene expression of the MBNL family of regulators of alternative splicing in various stages of colorectal cancer development, together with the MBNL-target splicing events in FOXP1 and EPB4IL3 genes and tumor-related CD44 variants. Materials and Methods: Samples of tumor tissue and non-malignant mucosa from 108 patients were collected. After RNA isolation and reverse transcription, the relative gene expression of a selected gene panel was tested by quantitative real-time PCR, followed by statistical analysis. Results: MBNL expression was decreased in tumor tissue compared to non-tumor mucosa. In addition, lower expression was observed for the variants of FOXP1 and EPB41L3, while higher expression in tumor tissue was detected both for total CD44 and its cancer-related variants 3 and 6. Transcript levels of the MBNL genes were not found to be related to any of the studied clinicopathological characteristics. Multiple significant associations were identified in the target gene panel, including higher transcript levels of FOXP1 and CD44v3 in patients with distant metastases and connections between recurrence-free survival
\end{abstract}

This article is freely accessible online.

Correspondence to: Pavel Pitule, Faculty of Medicine in Pilsen, Charles University, alej Svobody 76, 32300 Pilsen, Czech Republic. Tel: +42 0721365456,e-mail: pavel.pitule@lfp.cuni.cz

Key Words: Alternative splicing, RNA-binding proteins, MBNL regulatory factors, colorectal cancer. and altered levels of FOXP1 and CD44v3. Conclusion: Our results identified for the first-time deregulation of $M B N L$ genes in colorectal cancer. Down-regulation of their transcripts in tumor tissue compared to matched non-tumor mucosa can lead to transition of alternative splicing patterns towards a less differentiated phenotype, which highlights the importance of alternative splicing regulation for tumor growth and propagation.

Colorectal cancer (CRC) remains the third most commonly diagnosed malignancy in males and the second most commonly diagnosed cancer in females $(1,2)$. Globally, colorectal cancer is among the leading causes of cancer-related deaths $(3,4)$. Although the incidence of CRC has been steadily rising worldwide over the last few decades, especially in developing countries (3), the overall survival rate has increased as well with advances in targeted agents and cytotoxic chemotherapy $(4,5)$. Also, improvements in CRC screening result in disease detection at lower stages when it is easier to remove the tumor by surgery before metastatic spread occurs (6). In general, treatment choice is based on multiple factors, including clinical features (e.g. tumor location, stage at detection), demographic variables (e.g. sex, age at diagnosis, and familial risk), and characteristics of the tumor (e.g. microsatellite instability, somatic mutations) $(7,8)$.

In addition to common prognostic factors and therapeutic targets, evidence accumulated during the past decades has revealed novel markers. In particular, the importance of alternative splicing dysregulation during colorectal cancer development has been observed, opening new aspects of specific modifications of splicing regulatory proteins and pathologic splicing events in CRC $(9,10)$.

Alternative splicing (AS) is known as an important posttranscriptional process that enables formation of multiple 
distinct mRNAs from a single gene, which results in increased proteomic diversity with distinct variants having various structural and functional properties (11). AS represents a crucial regulatory mechanism of gene expression, cellular differentiation, and signal transduction (12), mediating different biological processes including erythropoiesis, neuronal differentiation or embryonic stem cell programming (13). Under normal conditions, AS is known as a versatile and powerful mechanism that is tightly regulated by splicing regulatory proteins. Regulation of AS is a complicated process and its misregulation drives production of aberrant protein isoforms, which may lead to cancer pathogenesis, muscular dystrophies or neurological diseases (14).

Splicing regulation is generally directed by regulatory sequences, which are cis-acting, and RNA-binding proteins (RBPs), which are trans-acting. The interactions of regulatory sequences and RBPs determine the resulting relative synthesis rate of protein isoforms. The most common mechanisms of alternative splicing misregulation originate from alterations in the levels and activity of RBPs (14). Multiple families as well as individual RBPs exist, some with ubiquitous expression and some highly restricted to particular tissue types or developmental stages. For instance, the heterogeneous nuclear ribonucleoproteins (hnRNPs), RBFOX2 or MATR3, are known as part of a larger RBP complex and are examples of ubiquitous splicing regulators (15). Examples of more specific RBPs include CELF (CUG-BP and ETR-3-like factors) and muscleblind-like (MBNL) families. The latter is the major focus of the presented study and consists of three genes, namely MBNL1, MBNL2 and MBNL3. Besides the primary MBNL function of AS regulators during mRNA maturation (16), they can also be involved in regulation of mRNA subcellular localization (17), mRNA stability control and alternative polyadenylation $(18,19)$.

The MBNL proteins are key regulators of precursor mRNA as they influence both alternative splicing (AS) and overall mRNA stability in mammals. During embryonic development, increased concentrations of MBNL1 and 2 lead to differentiation of embryonic stem cells by promoting a shift from embryonic to fetal and then to adult splice patterns of target mRNAs (20). Although all three paralogs of MBNL share homologous structures, including four zinc finger $(\mathrm{ZnF})$ domains essential for recognizing the same consensus sequence in pre-mRNA and mRNA targets, they are significantly different with respect to their functional specializations and distribution of expression patterns during embryonic and postnatal development (20). Both MBNL1 and 2 are expressed in a diverse range of adult tissues. MBNL1 appears to be the predominantly expressed member of the MBNL family, it promotes muscle differentiation and in most tissues it facilitates transitions from embryonic to fetal and from fetal to adult splicing patterns $(21,22)$. A significant exception to this rule is brain tissue where
MBNL2 is predominantly expressed (20). MBNL3 is mostly present at early stages of development, and later in the placenta, spleen and lung. In addition, MBNL3 appears to function in an opposing manner to MBNL1 and 2, as it has been reported to inhibit muscle differentiation (23). In pathophysiology, MBNLs' functional insufficiency results in mis-regulation of alternative splicing, alters target genes' isoform ratios and can cause cancers, muscular dystrophies, and neurological diseases (24). A majority of studies focus on pathologies associated with aberrant MBNL1 function while the roles of MBNL2 and MBNL3 have been less investigated $(16,21)$. The best-described disease related to the MBNL protein family dysregulation is myotonic dystrophy $(20,25)$. Deregulation of MBNL activity can also influence alternative splicing of factors controlling pluripotency and reprogramming, such as FOXP1 and CD44, which have been linked to cancer $(26,27)$. Recently, MBNL1 splicing deregulation in colorectal cancer was linked to colorectal cancer cells' resistance to oxidative stress, showing importance of MBNL1 regulated alternative splicing for survival of cancer cells (28).

In the present study, we address the question of whether alterations in the MBNL family expression can be linked to pathological and clinical behavior of colorectal cancer and whether they can be used as markers of prognosis and prediction of treatment efficiency. In addition to MBNL genes themselves, we analyzed a number of alternatively spliced isoforms of EPB41L3, FOXP1 and CD44 genes that were previously confirmed to be regulated by MBNL or are known for their abundant alternative splicing $(25,26)$.

\section{Materials and Methods}

Selection of genes studied. In the present study, we analyzed the transcript levels of three MBNL paralogs in colorectal cancer and selected variants of Forkhead Box P1 (FOXP1), Erythrocyte Membrane Protein Band 4.1 Like 3 (EPB41L3) and CD44 transcript variants 3 and 6 . To test the effect of MBNL activity on the alternative splicing of the target genes, we selected FOXP1 and EPB41L3 exons reported to be regulated by MBNL according to the study by Hong Han et al. (26). CD44 transcript variant 3 and CD44 transcript variant 6 were selected as particular isoforms of CD44 related to cancer diseases (29). In addition to serving as a potential marker for MBNL functional status, analysis of FOXP1, EPB41L3 and CD44 alternative splicing could bear important information given their own oncogenic potential.

Selection of reference genes - hypoxanthine phosphoribosyltransferase1 (HPRT1), Histidyl-TRNA Synthetase (HARS) and actin beta (ACTB) was based on existing literature data $(30,31)$ and our own experience.

Primer design. Quantitative real-time polymerase chain reaction (PCR) primers for the selected genes were designed using Primer3 software $(32,33)$ with special emphasis on exon/exon-junctionspanning assays. In case of special splicing variants, primers were designed to align into the exon of interest, common assays were 
Table I. List of primers used and their characteristics. Primers designated as var are specific for particular splice variants known to be regulated by MBNL; primers labeled as com are used to amplify other mRNA splice isoforms except the specific MBNL-regulated variant.

\begin{tabular}{|c|c|c|c|c|c|}
\hline Gene name & $\begin{array}{l}\text { Primer } \\
\text { type }\end{array}$ & $\begin{array}{c}\text { Primer sequence } \\
{\left[5^{\prime}-3^{\prime}\right]}\end{array}$ & $\begin{array}{c}\text { Amplicon } \\
\text { size [nt] }\end{array}$ & $\begin{array}{c}\text { GC content } \\
{[\%]}\end{array}$ & $\begin{array}{l}\text { Predicted melting } \\
\text { temperature }\left[{ }^{\circ} \mathrm{C}\right]\end{array}$ \\
\hline \multirow[t]{2}{*}{ АCTB } & Forward & CCAACCGCGAGAAGATGA & 97 & 56 & 60 \\
\hline & Reverse & CCAGAGGCGTACAGGGATAG & & 60 & 59 \\
\hline \multirow[t]{2}{*}{ HPRT1 } & Forward & TGACCTTGATTTATTTTGCATACC & 102 & 33 & 59 \\
\hline & Reverse & CGAGCAAGACGTTCAGTCCT & & 55 & 60 \\
\hline \multirow[t]{2}{*}{ HARS } & Forward & ATTGGGGTGGAGCGGATTTT & 78 & 0.5 & 60 \\
\hline & Reverse & TGTCTCCGTGGTCCGTATCT & & 0.55 & 60 \\
\hline \multirow[t]{2}{*}{ MBNL1 } & Forward & ATCGCCTGCTTTGATTCATT & 76 & 40 & 59 \\
\hline & Reverse & TTAAATGTGGGGGTGGATGA & & 45 & 60 \\
\hline \multirow[t]{2}{*}{ MBNL2 } & Forward & GCCCAGCAGATGCAATTTAT & 137 & 45 & 60 \\
\hline & Reverse & AACCCAACTCCAGGGGTTAC & & 55 & 60 \\
\hline \multirow[t]{2}{*}{ MBNL3 } & Forward & ATTCCTGGAAACCCACCTCT & 89 & 50 & 59 \\
\hline & Reverse & TGAAATTCTCGGCAAACCTC & & 45 & 60 \\
\hline \multirow[t]{2}{*}{ EPB41L3com } & Forward & AAAGAGGCCAAAGAGCAGCA & 115 & 50 & 60 \\
\hline & Reverse & GCAAGCTAAGTTATTCCTCTGGTC & & 46 & 59 \\
\hline \multirow[t]{2}{*}{ EPB41L3var } & Forward & ACCATGACCAGGAATAACTTAGCT & 101 & 42 & 60 \\
\hline & Reverse & AGTCAGTTGGGTTAGAAGAGGG & & 50 & 59 \\
\hline \multirow[t]{2}{*}{ FOXP1com } & Forward & CACGTGGAAGAATGCAGTGC & 88 & 55 & 60 \\
\hline & Reverse & CACTGTCCATACTGCCCCTT & & 55 & 59 \\
\hline \multirow[t]{2}{*}{ FOXP1var } & Forward & ACGTGGAAGGGTGCCATTC & 114 & 58 & 60 \\
\hline & Reverse & GCGGCCACGTTTAAACTCTT & & 50 & 59 \\
\hline \multirow[t]{2}{*}{$\mathrm{CD} 44$} & Forward & CCCAGATGGAGAAAGCTCTG & 113 & 55 & 60 \\
\hline & Reverse & GTTGTTTGCTGCACAGATGG & & 50 & 60 \\
\hline \multirow[t]{2}{*}{$\mathrm{CD} 44 \mathrm{v} 3$} & Forward & TCCCTGCTACCAATATGGACTC & 122 & 50 & 60 \\
\hline & Reverse & ACTCTGCTGCGTTGTCATTG & & 50 & 60 \\
\hline \multirow[t]{2}{*}{$\mathrm{CD} 44 \mathrm{v} 6$} & Forward & AGGAACAGTGGTTTGGCAAC & 68 & 50 & 60 \\
\hline & Reverse & CGAATGGGAGTCTTCTTTGG & & 50 & 60 \\
\hline
\end{tabular}

designed on exons typical for all other variants included in the NCBI RefSeq database at the time of primer design (10/2016). Designed primers were aligned to a non-redundant mRNA database using BLAST (34) to check for putative amplification of off-target sequences and to validate priming of desired variants. Primer sequences used in the study are summarized in Table I.

Selection of patients and collection of tissue samples. In total, 108 patients who underwent surgery for colorectal cancer at the Department of Surgery of University Hospital in Pilsen between years 2008 to 2016 were included in this retrospective study. All enrolled patients agreed to the processing of the samples by signing informed consent. The study was approved by the Ethical committee of the Faculty of Medicine and University Hospital in Pilsen and complied with the International Ethical Guidelines for Biomedical Research Involving Human Subjects. Clinical data were collected on 01/2020 by clinicians and anonymized before transfer for statistical analysis.

Tissue collection was performed within 20 min after the removal of the tissue from the patient for both tumor and non-tumor mucosa (anatomically the most distant tissue that was macroscopically healthy, in the range of $15-20 \mathrm{~cm}$ from the tumor location). Tissue samples with maximal size of $5 \mathrm{~mm}$ in the longest axis were gathered, immediately frozen in cryotubes (Thermo Fisher Scientific, Waltham, MA, USA) and stored at $-80^{\circ} \mathrm{C}$ (35).

Isolation of RNA and quality validation. A standard protocol for RNA isolation using TriReagent RT (MRC, USA) was used to isolate RNA from frozen samples. The tissue was removed from the cryotube and 
placed in liquid nitrogen in a mortar. The tissue was pulverized and transferred into an Eppendorf tube with $1 \mathrm{ml}$ TriReagent RT chilled to $4^{\circ} \mathrm{C}$ and total RNA was isolated according to the manufacturer's protocol. Total isolated RNA was dissolved in nuclease-free water (Ambion, Carslbad, CA, USA). RNA concentration was assessed by absorbance measurement using the Infinite M200 (Tecan, Männedorf, Switzerland) in the NanoQuant setting. RNA quality was assessed by agarose gel electrophoresis. Only samples with a $230 \mathrm{~nm} / 260 \mathrm{~nm}$ ratio $>1.7$ and samples with proper bands without degradation on agarose gel electrophoresis were used for further analysis.

Reverse transcription (DNase, PCR control). cDNA was synthetized according to the manufacturer's protocol, using $500 \mathrm{ng}$ of total RNA in $20 \mu \mathrm{l}$ reaction by RevertAid First Strand cDNA Synthesis Kit (THERMO SCIENTIFIC, Waltham, MA, USA). For priming of reverse transcription reaction, a combination of oligo(dT) 18 and random hexamer primers, each at $2.5 \mu \mathrm{M}$ final concentration, was used. The quality of cDNA and possible contamination by genomic DNA was assessed by a control PCR reaction (GAPDH amplification, 40 cycles) and agarose gel electrophoresis.

Quantitative real-time PCR. 5x HOT FIREPol ${ }^{\circledR}$ EvaGreen ${ }^{\circledR}$ qPCR SuperMix (Solis BioDyne, Tartu, Estonia) was used for the quantitative PCR. cDNA was diluted 100x and $2 \mu \mathrm{l}$ of cDNA were used in each reaction, having a final volume of $10 \mu$ l. Optimal cycling parameters and annealing temperatures were assessed by the measurement of sensitivity, specificity and efficiency of individual quantitative PCR reactions. CFX 96 quantitative real-time PCR cycler (Biorad, CA, USA) was used for the analysis.

Cycling parameters were: initial hold at $50^{\circ} \mathrm{C}$ for $20 \mathrm{~s}$ and initial denaturation at $95^{\circ} \mathrm{C}$ for $12 \mathrm{~min}$ followed by 45 cycles consisting of denaturation at $95^{\circ} \mathrm{C}$ for $15 \mathrm{~s}$ and annealing and extension at $60^{\circ} \mathrm{C}$ for $60 \mathrm{~s}$. Results were analyzed and basic statistical analysis was carried out using the Bio-Rad CFX Manager software.

Statistical analysis. Standard frequency tables and descriptive statistics were used to characterize the patient group. Relative transcript levels of measured genes in the tumor tissue (relative to adjacent non-tumor tissue) were expressed by $-\Delta \Delta \mathrm{Ct}$ values according to Livak et al. (36), with mean $\mathrm{Ct}$ of the above-listed reference genes used as internal control. Because of their mostly normal distribution (as reviewed in histograms and using ShapiroWilk test), data were analyzed using mainly parametric methods. One sample $t$-test against zero reference was used to test for significant up- or down-regulation.

In order to directly explore the relationship between MBNL expression and the levels of their target gene variant transcripts, $-\Delta \mathrm{Ct}$ values (i.e. differences between mean reference gene $\mathrm{Ct}$ and MBNL $\mathrm{Ct}$ ) of MBNL 1-3 were tested for correlation (using Kendall's tau) with the difference between the $\mathrm{Ct}$ values of FOXP1com and FOXP1var, and also with the Ct difference between EPB41L3com and EPB41L3var. The differences between the "com" and "var" $\mathrm{Ct}$ values represent the ratio of the variant transcript levels and the fact that they do not involve reference genes prevents the occurrence of potential false correlations caused by measurement noise in the reference genes' Ct values. This analysis was independently performed in tumor tissue and non-tumorous mucosa.

Associations between the transcript levels and clinical characteristics of the patients ( $\mathrm{T}$ - tumor stage, $\mathrm{N}$ - lymph node invasion, $\mathrm{M}$ - metastases, $\mathrm{G}$ - histological grade, UICC - classification
Table II. Characteristics of the analyzed colorectal cancer patients.

\begin{tabular}{|c|c|c|c|}
\hline Characteristic & Category & Number & $\%$ \\
\hline \multirow[t]{2}{*}{ Gender } & $\mathrm{F}$ & 44 & 40.7 \\
\hline & M & 64 & 59.3 \\
\hline \multirow[t]{3}{*}{ Age (in years) } & $30-50$ & 7 & 6.5 \\
\hline & $50-70$ & 57 & 52.8 \\
\hline & $>70$ & 44 & 40.7 \\
\hline \multirow[t]{5}{*}{ T stage } & $\mathrm{T} 1$ & 3 & 2.8 \\
\hline & $\mathrm{T} 2$ & 23 & 21.3 \\
\hline & $\mathrm{T} 3$ & 66 & 61.1 \\
\hline & $\mathrm{T} 4$ & 14 & 13.0 \\
\hline & Unknown & 2 & 1.9 \\
\hline \multirow[t]{5}{*}{$\mathrm{N}$} & No & 62 & 57.4 \\
\hline & N1 & 21 & 19.4 \\
\hline & $\mathrm{N} 2$ & 21 & 19.4 \\
\hline & $\mathrm{N} 3$ & 1 & 0.9 \\
\hline & Unknown & 3 & 2.8 \\
\hline \multirow[t]{3}{*}{ M } & M0 & 79 & 73.1 \\
\hline & M1 & 26 & 24.1 \\
\hline & Unknown & 3 & 2.8 \\
\hline \multirow[t]{4}{*}{ Histological grade } & G1 & 13 & 12.0 \\
\hline & G2 & 74 & 68.5 \\
\hline & G3 & 14 & 13.0 \\
\hline & Unknown & 7 & 6.5 \\
\hline \multirow[t]{5}{*}{ UICC staging } & $\mathrm{I}$ & 23 & 21.3 \\
\hline & II & 33 & 30.6 \\
\hline & III & 27 & 25.0 \\
\hline & IV & 24 & 22.2 \\
\hline & Unknown & 1 & 0.9 \\
\hline \multirow[t]{4}{*}{ Tumor location } & Right or transverse colon & 41 & 38.0 \\
\hline & Left or sigmoid colon & 30 & 27.8 \\
\hline & Rectum or rectosigmoid junction & 36 & 33.3 \\
\hline & Non-specific & 1 & 0.9 \\
\hline
\end{tabular}

F: Female; M: male; tumor classification based on TNM classification on malignant tumors with following categories: $\mathrm{T}$ stage: size of the primary tumor; $\mathrm{N}$ : degree of tumor spread in lymph nodes; M: presence of distant metastasis; G: histological tumor grade; UICC staging: tumor classification according to Union for International Cancer Control.

according to Union for International Cancer Control) were analyzed by two-sample t-test (difference between two groups), one-way ANOVA (testing for non-uniform means in multiple groups) and Kendall's tau (testing for increasing/decreasing trends across multiple ordinal categories). Recurrence-free survival (RFS) was determined from the date of surgery until the date of first documented disease recurrence or death. Overall survival (OS) was determined from the date of surgery until the date of death, regardless of its cause. Patients who had not progressed or died were censored at the date of the last follow-up. Significance of associations between transcripts and survival times was assessed using univariable Cox proportional hazards model (except for EPB41L3var, which was removed from survival analysis due to a small subset of patients with EPB41L3var measurements and survival data available). Prerequisites of the Cox model were checked by testing the scaled Schoenfeld residuals for correlation with observation time (which should not occur under the proportionality assumption), and by visually assessing the Martingale residuals (in relation to the covariate value) and the distribution of 


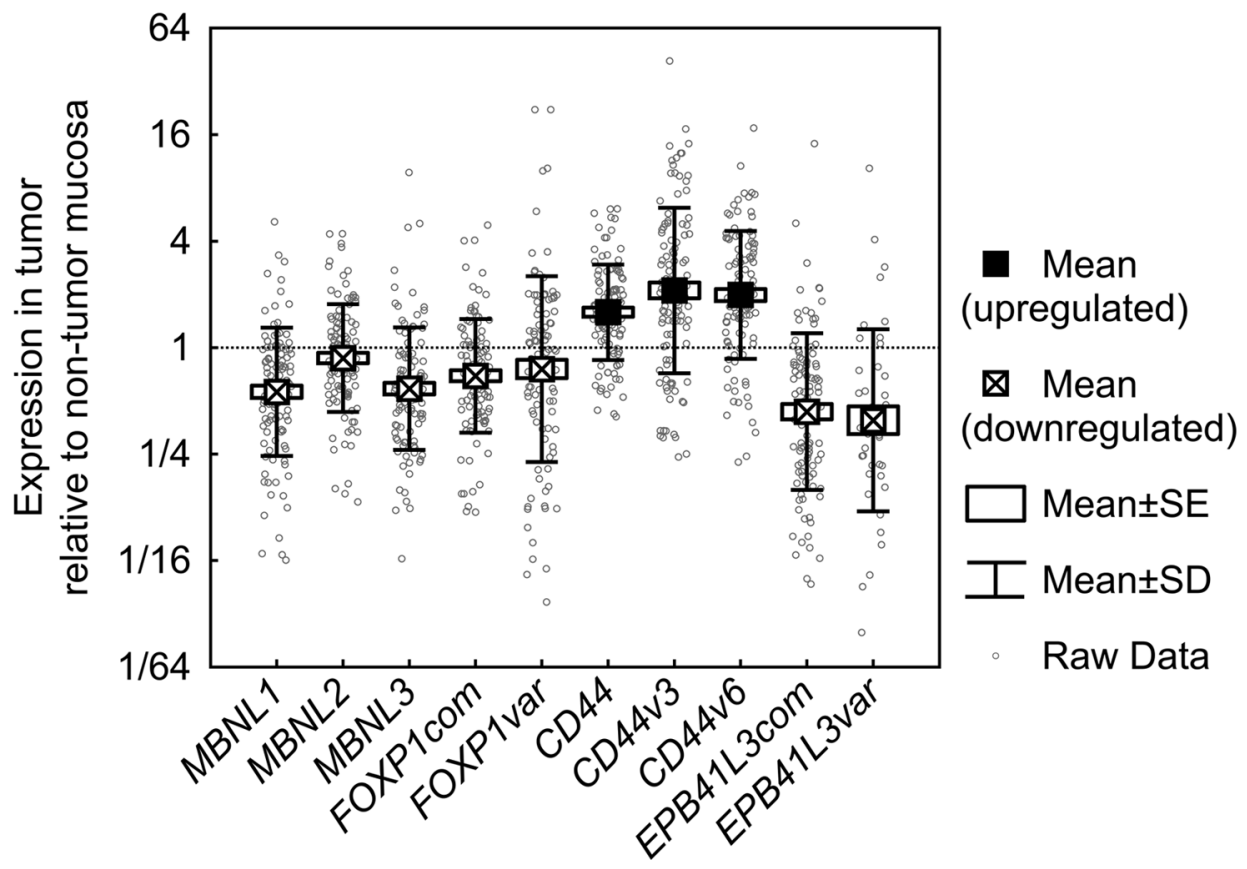

Figure 1. Expression ratio of candidate genes in tumor vs healthy tissue. All genes show significant deregulation in tumor tissue.

deviance residuals in order to confirm linearity and absence of overly influential observations, respectively. Discovered prognostic genes were subsequently tested for independence of other clinical factors using the multivariable Cox proportional hazards model.

In order to visualize the expression-survival associations and to detect possible non-proportional ones, significant or borderline results were reviewed using automated stratification. In this procedure, a threshold (cut-off) expression $(-\Delta \Delta \mathrm{Ct})$ value was independently determined for OS and RFS for each gene by an automated optimization process finding the threshold providing the lowest Cox-Mantel p-value in two-sample Kaplan-Meier survival analysis, which was finally verified using the Gehan-Wilcoxon test. This was done using a custom-written script in Matlab enumerating all possible stratifications (with a minimum group size empirically set to $20 \%$ of the whole cohort) according to the variable of interest.

All reported $p$-values are two-tailed, and the level of statistical significance was set at $\alpha=0.05$. False discovery rate (FDR) was controlled using the Benjamini-Hochberg procedure carried out upon the results of all significance test performed within the study. At the baseline significance level of 0.05 , the estimated FDR is $10 \%$, indicating $90 \%$ of the presented significant results to be true positives. A conservative overall FDR of $5 \%$ would require the individual significance level of 0.022 . Statistical processing and testing were performed in STATISTICA data analysis software system (StatSoft, Inc. 2013, Version 12, www.statsoft.com) and Matlab (2019b, MathWorks Inc., Natick, MA, USA).

\section{Results}

In the current study, we analyzed the expression of $3 \mathrm{MBNL}$ paralogs and variants of 3 target genes with transcription- variant-specific primers on a sample set of 108 patients. Descriptive statistics of the enrolled patients are summarized in Table II.

Focusing on the MBNL family, we observed a decrease in the level of all MBNL genes in tumor tissue compared to paired non-tumor samples (MBNL1 $p<0.001$, MBNL2 $p=0.047$, MBNL3 $p<0.001)$. It represents the first concise evidence that MBNL genes are deregulated in colorectal cancer. Despite the deregulation on the transcript level, no correlation between MBNL1, 2 and 3 transcripts and clinical parameters was observed in our patient set.

Deregulation of transcripts was detected also in the target gene panel, with CD44 ( $p<0.001)$, CD44v3 $(p<0.001)$ and CD44v6 $(p<0.001)$ showing higher levels in tumor tissue, and FOXP1com $(p<0.001)$, FOXP1var $(p=0.024)$, EPB41L3com $(p<0.001)$ and EPB41L3var $(p<0.001)$ being up-regulated in non-tumor samples (Figure 1).

Subsequent correlation analysis between MBNL expression and the target gene variant transcript ratios showed higher expression of MBNL1 and MBNL3 to be significantly associated with increased variant transcript levels of FOXP1var (MBNL3 in tumor tissue $p=0.046$; MBNL1 in non-tumor mucosa $p=0.024$; MBNL3 in non-tumorous mucosa $p=0.011$ ). Similarly, MBNL3 overexpression was linked to increased variant transcript ratio of EPB41L3var in non-tumorous mucosa $(p=0.002)$. Contrastingly to that, higher expression of MBNL2 in the tumor was linked to lower transcript levels of EPB41L3var $(p=0.011)$. 

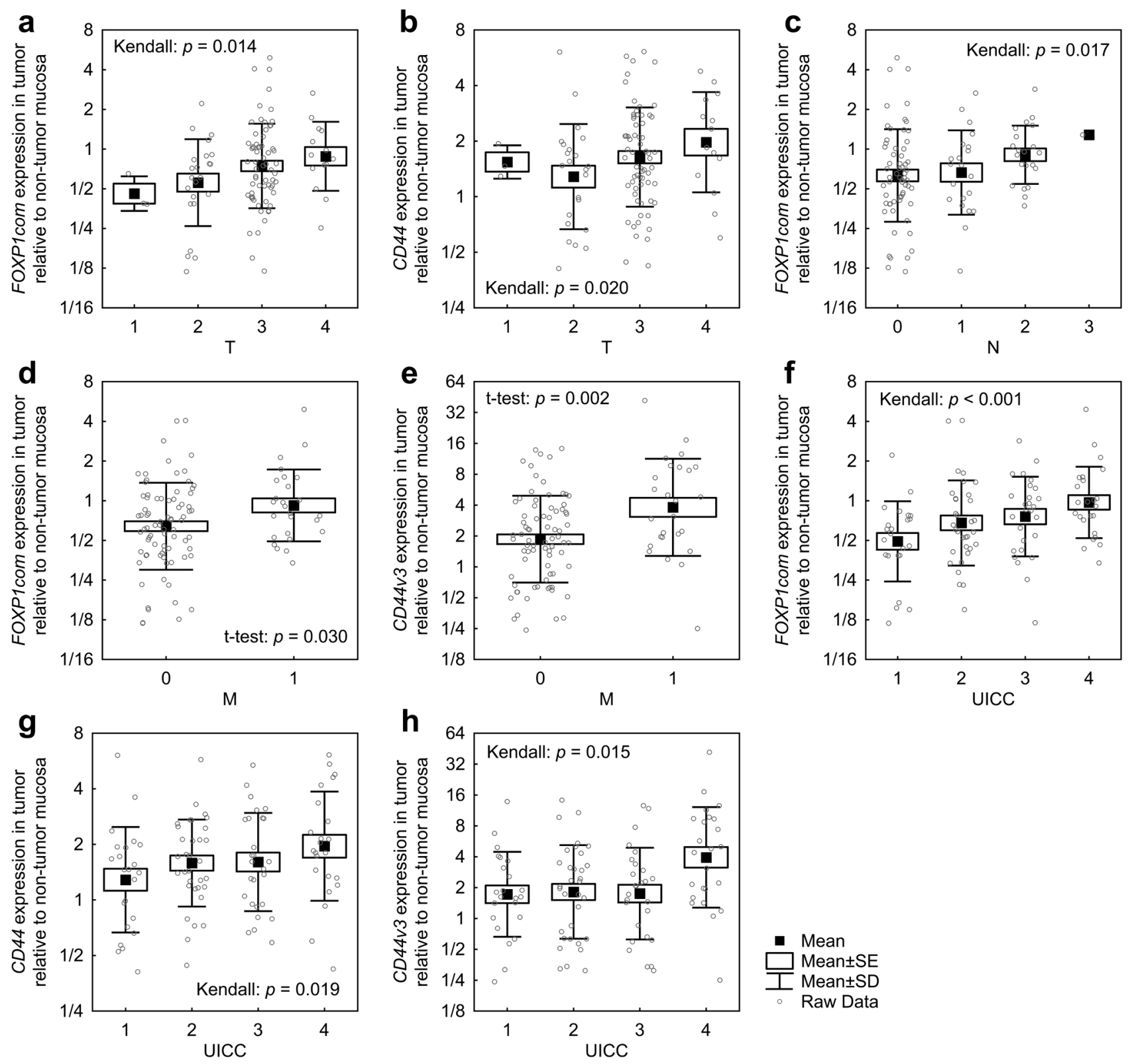

Figure 2. Expression of candidate genes according to $T, N, M, G$, and UICCC in tumor tissue relative to healthy tissue. (a) distribution of FOXP1com expression change according to $T$ stage; (b) distribution of $C D 44$ expression change according to $T$ stage; (c) distribution of FOXPIcom expression change according to $\mathrm{N} ;(d)$ distribution of FOXP1com expression change according to $M$; (e) distribution of CD44v 3 expression change according to $M$; $(f)$ distribution of FOXP1com expression change according to UICC score; $(g)$ distribution of CD44 expression change according to UICC score; (h) distribution of CD44v3 expression change according to UICC score.

Next, we analyzed the associations of the expression of target genes with clinical parameters. The analysis detected increasing trends for FOXP1com with both $\mathrm{T}$ and $\mathrm{N}$ advancement ( $\mathrm{T}$ staging: Kendall correlation: $\tau=0.16$, $p=0.014 ; \mathrm{N}$ : Kendall correlation: $\tau=0.16, p=0.017$ ) and also for CD44 with T-stage advancement (Kendall correlation: $\tau=0.15, \quad p=0.020)$. Furthermore, the comparison of expression between groups with and without distant metastasis at the time of surgery revealed significantly higher levels of FOXP1com $(p=0.030)$ and CD44v3 $(p=0.020)$ expression in the metastasis group. The overall UICC staging score was significantly correlated with expression of FOXP1com (Kendall correlation: $\tau=0.23, p<0.001$ ), CD44 (Kendall correlation: $\tau=0.15, \quad p=0.019$ ) and CD44v3 
Table III. Results of the univariable Cox proportional hazard models.

\begin{tabular}{|c|c|c|c|c|c|c|}
\hline \multirow[t]{2}{*}{ Predictor variable } & \multicolumn{3}{|c|}{ OS } & \multicolumn{3}{|c|}{ RFS } \\
\hline & $p$-Value & $\mathrm{HR}^{1}$ & prop. test ${ }^{2}$ & $p$-Value & $\mathrm{HR}^{1}$ & prop. test ${ }^{2}$ \\
\hline MBNL1 & 0.315 & 1.184 & 0.155 & 0.227 & 1.190 & 0.398 \\
\hline MBNL2 & 0.924 & 1.019 & 0.040 & 0.926 & 0.985 & 0.073 \\
\hline MBNL3 & 0.928 & 0.984 & 0.377 & 0.553 & 0.911 & 0.731 \\
\hline FOXP1com & 0.002 & 1.732 & 0.514 & 0.070 & 1.309 & 0.977 \\
\hline FOXP1var & $<0.001$ & 1.503 & 0.298 & 0.030 & 1.262 & 0.902 \\
\hline CD44 & 0.225 & 1.320 & 0.918 & 0.268 & 1.236 & 0.608 \\
\hline CD44v3 & 0.023 & 1.358 & 0.647 & 0.016 & 1.333 & 0.864 \\
\hline CD44v6 & 0.097 & 1.356 & 0.335 & 0.449 & 1.114 & 0.236 \\
\hline EPB41L3com & 0.583 & 1.080 & 0.778 & 0.281 & 1.124 & 0.440 \\
\hline
\end{tabular}

${ }^{1} \mathrm{HR}$ : Hazard ratio; relative change of risk per each unit of $-\Delta \Delta \mathrm{Ct}$ value increase; ${ }^{2}$ proportionality test; $p$-values of the Spearman correlation analysis between the scaled Schoenfeld residuals and observation times. Significant values (in bold) indicate that the proportionality assumption of the Cox model might not have been met.

(Kendall correlation: $\tau=0.16, p=0.015$ ). When considering tumor grading, we observed significantly non-uniform expression of CD44v6 across different grades (G1-G3) (oneway ANOVA: $\mathrm{F}=3.90, p=0.024$ ) (Figure 2).

Using a univariable Cox proportional hazards model, proportional associations of the measured expression levels with overall survival were found for FOXPcom $(p=0.002)$ with a hazard rate (HR) of 1.73 per unit of $-\Delta \Delta C t$ value (i.e. each doubling of the expression ratio between the tumor tissue and macroscopically healthy mucosa increases the risk of death 1.73-fold), FOXP1var $(p<0.001, \mathrm{HR}=1.50)$, and CD44v3 ( $p=0.023, \mathrm{HR}=1.36$ ) (Table III and Figure 3). For FOXP1com and FOXP1var, the association with OS was proven to be independent of other clinical factors by the multivariable Cox model (Table IV). Recurrence-free survival was significantly influenced by FOXP1var $(p=0.030, \mathrm{HR}=1.26)$ and $\mathrm{CD} 44 \mathrm{v} 3(p=0.016, \mathrm{HR}=1.33)$, both of which showed independent prognostic ability in the multivariable setting (Table V). Automated determination of threshold values providing the best separation of groups confirmed these results (Figure 4).

\section{Discussion}

In the current study, we report significant deregulation of transcripts of the MBNL gene family in colorectal carcinoma. The MBNL proteins (MBNL1, MBNL2, MBNL3) are important regulators of alternative splicing and their increased activity promotes a switch from embryonic to adult AS pattern, represses pluripotency network and promotes differentiation. It is known that the expression profile of three MBNL paralogs and their correlated effect with the set of transcription factors might alter multiple splicing events $(26,37)$. Our data show a decrease of MBNL expression in tumor tissue compared to matched nontumorous intestinal mucosa, and also simultaneous changes in the expression of splice-variants that are known to be regulated by $\mathrm{MBNL}(24,38)$. Also, our results show a weakly significant, yet consistent relationship between the expression of MBNL1 and 3, and the levels of their target variant transcripts of FOXP1 and EPB41L3. Marginally significant associations were observed between the expression of the studied genes and T, N, M, G and UICC clinical factors, with minute differences in gene expression among individual groups.

The observed down-regulation of transcripts of all three genes of the MBNL family in colorectal cancer tissue may promote a less differentiated phenotype of the malignant cells. Previous studies proposed a role of the MBNL proteins in the genesis of various tumor types. It has been shown that MBNL1 inhibits invasiveness and migratory capacity of cancer cells (39), including metastatic potential of colorectal cells in vitro (40). Down-regulation of MBNL3 was observed to be a crucial step in leukaemia stem cell renewal (27). On the other hand, MBNL2 is believed to be a driver of hypoxia adaptation, which is necessary for proliferation and migration of cancer cells in lung and breast cancer, and MBNL2 is thus considered a pro-oncogene in these cancer types (41). The function of the individual MBNL family members may therefore be very different and they can regulate particular alternative spicing patterns depending on the disease type and cellular context. In addition, the function of MBNL can be regulated by their own alternative splicing, as was described for MBNL exon 7 in the case of prostate cancer (42). Although we detected down-regulation of all members of the MBNL family, which is in line with their supposed tumor suppressor role, we detected neither an association of MBNL expression and T, N, M, G and UICC clinical factors in our 

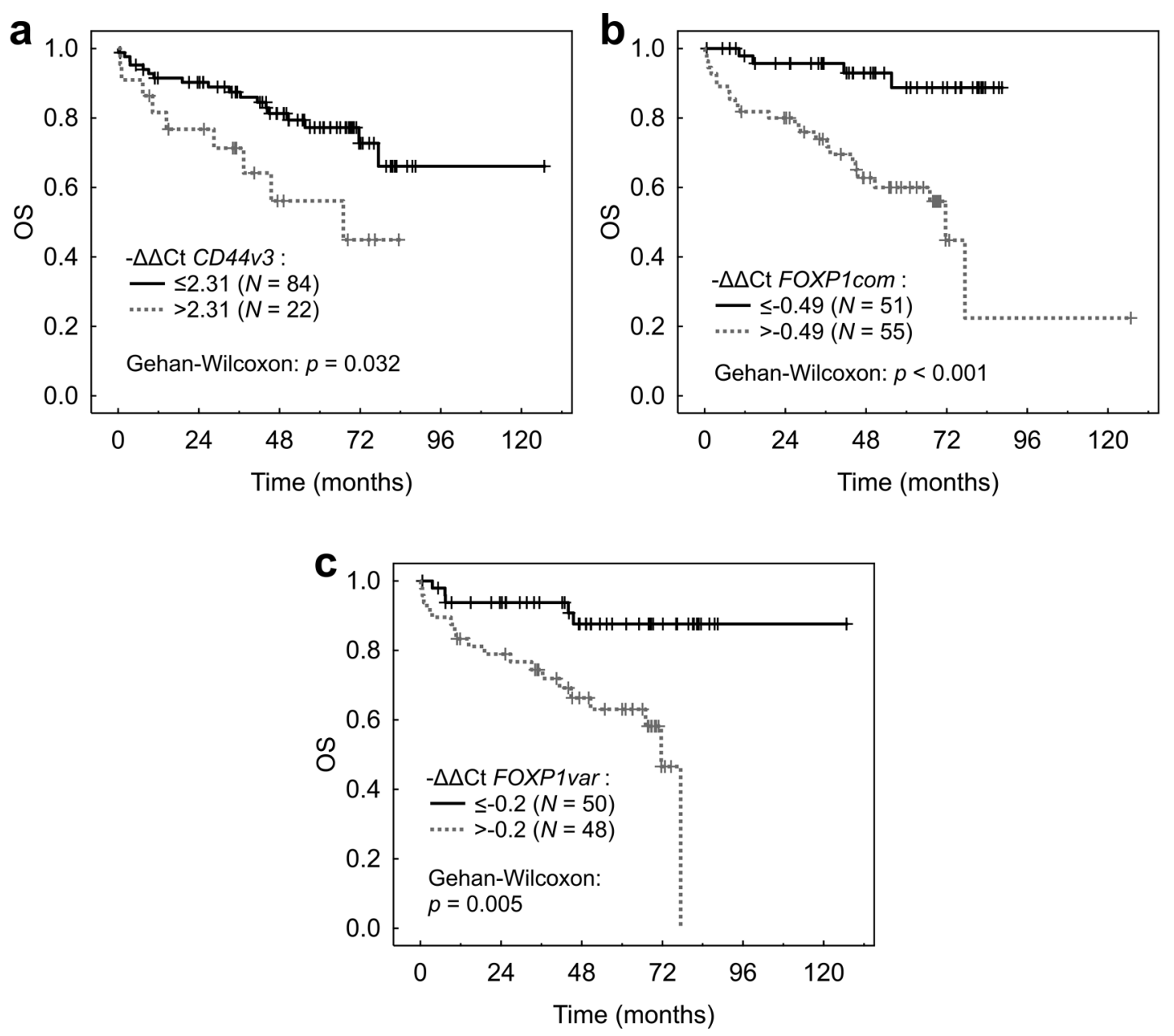

Figure 3. Kaplan-Meier overall survival curves based on optimized gene expression level groups; (a) CD44v3 (b) FOXP1com (c) FOXP1var.

data, nor any significant influence on patient survival. This indicates MBNL down-regulation as a significant marker of colorectal malignancy independent of disease progression, without direct manifestation of their down-regulation at the level of clinicopathological parameters.

We further examined expressions of additional genes, whose alternative splicing was shown to be under the MBNL proteins' regulation, and with implied role in cancer pathophysiology. The MBNL activity influences splicing of FOXP1 by promoting exclusion of exons that activate pluripotency genes and correspond to a stem cell-like phenotype $(26,43)$. Down-regulation of MBNL might thus contribute to pluripotency network engagement in cancer cells through FOXP1. Overall, the results of previous studies on the role of FOXP1 in cancer are controversial, suggesting both roles - as an oncogene as well as tumor suppressor depending on the tumor type. In our data, we observed significantly lower expression of FOXP1 in tumor cells, supporting previous findings in colorectal cancer $(43,44)$. Unexpectedly, FOXP1 expression was positively associated with disease progression in terms of tumor invasion, node involvement and presence of distant metastasis. Moreover, higher expression of FOXP1 was independently associated with shortened overall survival. These results seem to be in contrast with a previous study, where absence of FOXP1 was associated with decreased survival (43). Our results support the view of a more complex pattern of the FOXP1 factor involvement, possibly dependent on disease stage and on expression of particular isoforms. Under the condition of MBNL down-regulation, transcript levels of FOXP1 might correlate with a less differentiated cell phenotype.

Cancer tissue cells also displayed enhanced expression of CD44 and its alternative splice variants CD44v3 and CD44v6. CD44 functions as an adhesion molecule in cell-cell and cell- 

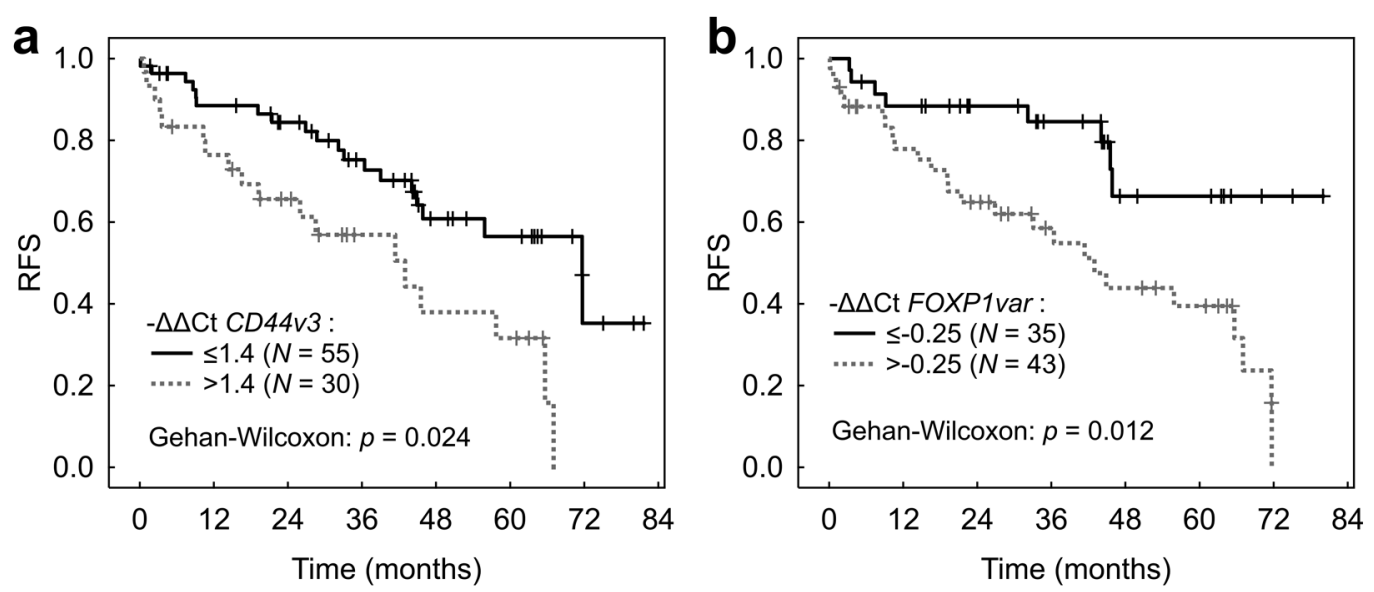

Figure 4. Kaplan-Meier recurrence free survival curves based on optimized gene expression level groups; a) CD44v3 and b) FOXP1var.

Table IV. Results of the multivariable Cox proportional hazard model for OS.

\begin{tabular}{|c|c|c|c|}
\hline Predictor variable & Category & $\begin{array}{l}\text { Relative risk } \\
(95 \% \mathrm{CI})\end{array}$ & $p$-Value \\
\hline \multirow[t]{2}{*}{ Gender } & Female & 1 & 0.100 \\
\hline & Male & $2.271(0.855-6.028)$ & \\
\hline \multirow[t]{2}{*}{ Age } & $<70$ & 1 & 0.013 \\
\hline & $\geq 70$ & $3.781(1.329-10.757)$ & \\
\hline \multirow[t]{2}{*}{$\mathrm{T}$} & $\mathrm{T} 1$ or $\mathrm{T} 2$ & 1 & 0.151 \\
\hline & $\mathrm{T} 3$ or $\mathrm{T} 4$ & $2.707(0.695-10.541)$ & \\
\hline \multirow[t]{2}{*}{$\mathrm{N}$} & No & 1 & 0.132 \\
\hline & N1 or higher & $2.035(0.807-5.133)$ & \\
\hline \multirow[t]{2}{*}{ M } & 0 & 1 & 0.338 \\
\hline & 1 & $28.072(0.031-25740)$ & \\
\hline \multirow[t]{2}{*}{ Surgical radicality } & R0 & 1 & 0.711 \\
\hline & $\mathrm{P}$ & $0.276(0-250.506)$ & \\
\hline \multirow[t]{2}{*}{ Chemo/radiotherapy } & Yes & 1 & 0.687 \\
\hline & No & $1.236(0.441-3.465)$ & \\
\hline \multirow[t]{2}{*}{$-\Delta \Delta \mathrm{Ct} C D 44 v 3$} & $\leq 2.31$ & 1 & 0.083 \\
\hline & $>2.31$ & $2.531(0.887-7.226)$ & \\
\hline \multirow[t]{2}{*}{$-\Delta \Delta \mathrm{Ct}$ FOXP1com } & $\leq-0.49$ & 1 & 0.010 \\
\hline & $>-0.49$ & $4.630(1.438-14.907)$ & \\
\hline \multirow[t]{2}{*}{$-\Delta \Delta C t$ FOXP1var } & $\leq-0.2$ & 1 & 0.000 \\
\hline & $>-0.2$ & $8.383(2.677-26.248)$ & \\
\hline
\end{tabular}

Significant $p$-Values are shown in bold.

matrix interactions and as a receptor in signal transduction, proposed to regulate tumor invasiveness and replication. The observation of CD44 up-regulation is consistent with a vast body of previous studies, however its role as a prognostic marker is not fully clear (45). Recent results of a meta-analysis proposed its role as a negative prognostic marker (46). This supports our observation of high CD44 expression being associated with tumor invasion and overall UICC staging.
Table V. Results of the multivariable Cox proportional hazard model for $R F S$.

\begin{tabular}{|c|c|c|c|}
\hline Predictor variable & Category & $\begin{array}{l}\text { Relative risk } \\
(95 \% \mathrm{CI})\end{array}$ & $p$-Value \\
\hline Gender & $\begin{array}{l}\text { Female } \\
\text { Male }\end{array}$ & $\begin{array}{c}1 \\
1.669(0.751-3.713)\end{array}$ & 0.209 \\
\hline Age & $\begin{array}{l}<70 \\
\geq 70\end{array}$ & $\begin{array}{c}1 \\
2.420(1.052-5.568)\end{array}$ & 0.038 \\
\hline $\mathrm{T}$ & $\begin{array}{l}\mathrm{T} 1 \text { or } \mathrm{T} 2 \\
\mathrm{~T} 3 \text { or } \mathrm{T} 4\end{array}$ & $\begin{array}{c}1 \\
1.218(0.426-3.483)\end{array}$ & 0.714 \\
\hline $\mathrm{N}$ & $\begin{array}{l}\text { N0 } \\
\text { N1 or higher }\end{array}$ & $\begin{array}{c}1 \\
2.222(1.006-4.91)\end{array}$ & 0.048 \\
\hline M & $\begin{array}{l}0 \\
1\end{array}$ & $\begin{array}{c}1 \\
0.761(0.078-7.436)\end{array}$ & 0.815 \\
\hline Surgical radicality & $\begin{array}{l}\text { R0 } \\
\text { P }\end{array}$ & $\begin{array}{c}1 \\
6.489(0.705-59.75)\end{array}$ & 0.099 \\
\hline Chemo/radiotherapy & $\begin{array}{l}\text { Yes } \\
\text { No }\end{array}$ & $\begin{array}{c}1 \\
1.337(0.560-3.194)\end{array}$ & 0.513 \\
\hline$-\Delta \Delta \mathrm{Ct} \quad \mathrm{CD} 44 \mathrm{v} 3$ & $\begin{array}{l}\leq 1.4 \\
>1.4\end{array}$ & $\begin{array}{c}1 \\
2.345(1.059-5.196)\end{array}$ & 0.036 \\
\hline$-\Delta \Delta \mathrm{Ct}$ FOXP1var & $\begin{array}{l}\leq-0.25 \\
>-0.25\end{array}$ & $\begin{array}{c}1 \\
3.006(1.234-7.325)\end{array}$ & 0.015 \\
\hline
\end{tabular}

Significant $p$-Values are shown in bold.

As the CD44 is expressed in various alternatively spliced variants, we further focused on an analysis of CD44v3 and CD44v6, which have been proposed to play a direct role in cancerogenesis $(47,48)$. Down-regulation of MBNL3 was shown to activate the pluripotency network and CD44v3 overexpression in chronic myeloid leukemia (27). A study with colon cancer cell lines proposed a role of CD44v3 in tumor invasiveness (49). CD44v6 is present in colorectal 
cancer stem cells, required for their ability to form metastasis (47) and enhancing their resistance to chemotherapy $(50,51)$. Both variants have been suggested as prognostic markers in colorectal cancer, with a probably more established role of CD44v6 (38, 52, 53).

We show associations of alternative CD44 variants with several clinicopathological parameters of disease progression. The CD44v6 correlated with tumor grading progression, while expression of CD44v3 was higher in patients with distant metastasis and correlated with the overall UICC score. The higher expression of CD44v3 was also associated with a worse survival rate, although without conclusively proven prognostic independence. This finding highlights the role of CD44v3 next to CD44v6 as an important marker with potential prognostic value.

The up-regulation of stem cell-like variants CD44v3 and CD44v6 is in line with the observed down-regulation of MBNL and concurrent switch to stem cell phenotype with high potential towards pluripotency and invasiveness.

Another gene whose expression is associated with extensive alternative splicing is the gene coding for cytoskeletal adaptor protein EPB41L3, which also acts as an important proliferation regulator. It has been demonstrated that alternative splicing of EPB41L3 is involved in differentiation of epithelial cells (54). The existing evidence is consistent with the role of EPB41L3 as a tumor suppressor (55). In line with this, we observed down-regulation of EPB41L3 in colorectal cancer tissue.

\section{Conclusion}

In conclusion, our results highlight the role of alternative splicing as an important mechanism in colorectal cancer pathogenesis. Alternative splicing, in addition to transcription changes, modulates gene expression to promote oncogenesis. Specifically, our data suggest a potential shift of the observed gene expressions towards stem-cell variants, associated with lower differentiation, pluripotency network engagement and enhanced invasiveness.

Altogether, in this study we have tried to advance our understanding of alternative splicing regulators as important markers of cancer progression and open the door for the further systematic study of alternative splicing regulation in colorectal cancer and other malignancies.

\section{Conflicts of Interest}

The Authors declare no conflicts of interest.

\section{Authors' Contributions}

Conceptualization, P.P.; Methodology, N.N., P.P.; Formal analysis, P.H.; Funding acquisition, P.P., P.K. and V.L.; Investigation, N.N.,
P.K., R.P. and J.R.; Project administration, P.P.; Resources, O.V., J.B., R.P. and J.R.; Supervision, P.P. and V.L.; Visualization, P.H.; Writing - original draft, N.N., F.Z. and A.N.; Writing - review and editing, P.P. and P.H.

\section{Acknowledgements}

The Authors would like to acknowledge the precious help from our technical assistant Eva Kralovcova who helped to successful completion of experiments related to the presented project. This study was supported by Centrum of clinical and experimental liver surgery UNCE/MED/006, GAUK 196217 and Charles University Research Fund (Progres Q39).

\section{References}

1 Bray F, Ferlay J, Soerjomataram I, Siegel RL, Torre LA and Jemal A: Global cancer statistics 2018: GLOBOCAN estimates of incidence and mortality worldwide for 36 cancers in 185 countries. CA Cancer J Clin 68(6): 394-424, 2018. PMID: 30207593. DOI: $10.3322 /$ caac. 21492

2 Ferlay J, Colombet M, Soerjomataram I, Mathers C, Parkin DM, Piñeros M, Znaor A and Bray F: Estimating the global cancer incidence and mortality in 2018: GLOBOCAN sources and methods. Int J Cancer 144(8): 1941-1953, 2019. PMID: 30350310. DOI: 10.1002/ijc.31937

3 Soriano LC, Soriano-Gabarró M and García Rodríguez LA: Trends in the contemporary incidence of colorectal cancer and patient characteristics in the United Kingdom: A population-based cohort study using the health improvement network. BMC Cancer 18(1): 402, 2018. PMID: 29636012. DOI: 10.1186/s12885-018-4265-1

4 Schmoll HJ, Van Cutsem E, Stein A, Valentini V, Glimelius B, Haustermans K, Nordlinger B, van de Velde CJ, Balmana J, Regula J, Nagtegaal ID, Beets-Tan RG, Arnold D, Ciardiello F, Hoff P, Kerr D, Köhne CH, Labianca R, Price T, Scheithauer W, Sobrero A, Tabernero J, Aderka D, Barroso S, Bodoky G, Douillard JY, El Ghazaly H, Gallardo J, Garin A, Glynne-Jones R, Jordan K, Meshcheryakov A, Papamichail D, Pfeiffer P, Souglakos I, Turhal S and Cervantes A: ESMO consensus guidelines for management of patients with colon and rectal cancer. a personalized approach to clinical decision making. Ann Oncol 23(10): 2479-2516, 2012. PMID: 23012255. DOI: $10.1093 /$ annonc/mds236

5 Targeted Therapy Drugs for Colorectal Cancer. Available at: https//www.cancer.org/cancer/colon-rectal-cancer/treating/ targeted-therapy.html [Last accessed on December 7, 2019]

6 Surgery for Colon Cancer. Available at: https://www. cancer.org/cancer/colon-rectal-cancer/treating/colon-surgery.html [Last accessed on December 7, 2019]

7 Marzouk $\mathrm{O}$ and Schofield J: Review of histopathological and molecular prognostic features in colorectal cancer. Cancers (Basel) 3(2): 2767-2810, 2011. PMID: 24212832. DOI: $10.3390 /$ cancers 3022767

8 Yu Y, Carey M, Pollett W, Green J, Dicks E, Parfrey P, Yilmaz YE and Savas S: The long-term survival characteristics of a cohort of colorectal cancer patients and baseline variables associated with survival outcomes with or without time-varying effects. BMC Med 17(1): 150, 2019. PMID: 31352904. DOI: 10.1186/s12916-019-1379-5 
9 Liu J, Li H, Shen S, Sun L, Yuan Y and Xing C: Alternative splicing events implicated in carcinogenesis and prognosis of colorectal cancer. J Cancer 9(10): 1754-1764, 2018. PMID: 29805701. DOI: $10.7150 /$ jca.24569

10 García-Cárdenas JM, Guerrero S, López-Cortés A, ArmendárizCastillo I, Guevara-Ramírez P, Pérez-Villa A, Yumiceba V, Zambrano AK, Leone PE and Paz-Y-Miño C: Posttranscriptional regulation of colorectal cancer: A focus on RNAbinding proteins. Front Mol Biosci 6: 65, 2019. PMID: 31440515. DOI: $10.3389 / \mathrm{fmolb} .2019 .00065$

11 Danan-Gotthold M, Golan-Gerstl R, Eisenberg E, Meir K, Karni $\mathrm{R}$ and Levanon EY: Identification of recurrent regulated alternative splicing events across human solid tumors. Nucleic Acids Res 43(10): 5130-5144, 2015. PMID: 25908786. DOI: $10.1093 / \mathrm{nar} / \mathrm{gkv} 210$

12 Wang Y, Liu J, Huang BO, Xu YM, Li J, Huang LF, Lin J, Zhang J, Min QH, Yang WM and Wang XZ: Mechanism of alternative splicing and its regulation. Biomed Rep 3(2): 152158, 2015. PMID: 25798239. DOI: 10.3892/br.2014.407

13 Manley JL: Mechanisms of alternative splicing of pre-mRNA. Columbia University, New York City, NY, USA. Available at: http://grantome.com/grant/NIH/R01-GM048259-25 [Last accessed on March 29, 2021]

14 Zhang J and Manley JL: Misregulation of pre-mRNA alternative splicing in cancer. Cancer Discov 3(11): 1228-1237, 2013. PMID: 24145039. DOI: 10.1158/2159-8290.CD-13-0253

15 Dassi E: Handshakes and Fights: The regulatory interplay of RNA-binding proteins. Front Mol Biosci 4: 67, 2017. PMID: 29034245. DOI: 10.3389/fmolb.2017.00067

16 Taylor K, Sznajder LJ, Cywoniuk P, Thomas JD, Swanson MS and Sobczak K: MBNL splicing activity depends on RNA binding site structural context. Nucleic Acids Res 46(17): 91199133, 2018. PMID: 29955876. DOI: 10.1093/nar/gky565

17 Ho TH, Charlet-B N, Poulos MG, Singh G, Swanson MS and Cooper TA: Muscleblind proteins regulate alternative splicing. EMBO J 23(15): 3103-3112, 2004. PMID: 15257297. DOI: 10.1038/sj.emboj.7600300

18 Batra R, Manchanda M and Swanson MS: Global insights into alternative polyadenylation regulation. RNA Biol 12(6): 597-602, 2015. PMID: 25892335. DOI: 10.1080/15476286.2015.1040974

19 Wang ET, Cody NA, Jog S, Biancolella M, Wang TT, Treacy DJ, Luo S, Schroth GP, Housman DE, Reddy S, Lécuyer E and Burge CB: Transcriptome-wide regulation of pre-mRNA splicing and mRNA localization by muscleblind proteins. Cell 150(4): 710-724, 2012. PMID: 22901804. DOI: 10.1016/j.cell.2012. 06.041

20 Konieczny P, Stepniak-Konieczna E and Sobczak K: MBNL proteins and their target RNAs, interaction and splicing regulation. Nucleic Acids Res 42(17): 10873-10887, 2014. PMID: 25183524. DOI: 10.1093/nar/gku767

21 Holt I, Jacquemin V, Fardaei M, Sewry CA, Butler-Browne GS, Furling D, Brook JD and Morris GE: Muscleblind-like proteins: Similarities and differences in normal and myotonic dystrophy muscle. Am J Pathol 174(1): 216-227, 2009. PMID: 19095965. DOI: 10.2353 /ajpath.2009.080520

22 Davis J, Salomonis N, Ghearing N, Lin SC, Kwong JQ, Mohan A, Swanson MS and Molkentin JD: MBNL1-mediated regulation of differentiation RNAs promotes myofibroblast transformation and the fibrotic response. Nat Commun 6: 10084, 2015. PMID: 26670661. DOI: 10.1038/ncomms 10084
23 Lee KS, Cao Y, Witwicka HE, Tom S, Tapscott SJ and Wang EH: RNA-binding protein Muscleblind-like 3 (MBNL3) disrupts myocyte enhancer factor 2 (Mef2) \{beta\}-exon splicing. J Biol Chem 285(44): 33779-33787, 2010. PMID: 20709755. DOI: 10.1074/jbc.M110.124255

24 Wagner SD, Struck AJ, Gupta R, Farnsworth DR, Mahady AE, Eichinger K, Thornton CA, Wang ET and Berglund JA: Dosedependent regulation of alternative splicing by MBNL proteins reveals biomarkers for myotonic dystrophy. PLoS Genet 12(9): e1006316, 2016. PMID: 27681373. DOI: 10.1371/ journal.pgen.1006316

25 Huang H, Wahlin KJ, McNally M, Irving ND and Adler R: Developmental regulation of muscleblind-like (MBNL) gene expression in the chicken embryo retina. Dev Dyn 237(1): 286296, 2008. PMID: 18095352. DOI: 10.1002/dvdy.21408

26 Han H, Irimia M, Ross PJ, Sung HK, Alipanahi B, David L, Golipour A, Gabut M, Michael IP, Nachman EN, Wang E, Trcka D, Thompson T, O'Hanlon D, Slobodeniuc V, Barbosa-Morais NL, Burge CB, Moffat J, Frey BJ, Nagy A, Ellis J, Wrana JL and Blencowe BJ: MBNL proteins repress ES-cell-specific alternative splicing and reprogramming. Nature 498(7453): 241245, 2013. PMID: 23739326. DOI: 10.1038/nature12270

27 Holm F, Hellqvist E, Mason CN, Ali SA, Delos-Santos N, Barrett CL, Chun HJ, Minden MD, Moore RA, Marra MA, Runza V, Frazer KA, Sadarangani A and Jamieson $\mathrm{CH}$ : Reversion to an embryonic alternative splicing program enhances leukemia stem cell self-renewal. Proc Natl Acad Sci USA 112(50): 15444-15449, 2015. PMID: 26621726. DOI: 10.1073/pnas.1506943112

28 Chen YS, Liu CW, Lin YC, Tsai CY, Yang CH and Lin JC: The SRSF3-MBNL1-Acin 1 circuit constitutes an emerging axis to lessen DNA fragmentation in colorectal cancer via an alternative splicing mechanism. Neoplasia 22(12): 702-713, 2020. PMID: 33142236. DOI: 10.1016/j.neo.2020.10.002

29 Colorectal Cancer-Patient Version - National Cancer Institute. Available at: https://www.cancer.gov/types/colorectal [Last accessed on December 11, 2019]

30 Kozera B and Rapacz M: Reference genes in real-time PCR. J Appl Genet 54(4): 391-406, 2013. PMID: 24078518. DOI: 10.1007/s13353-013-0173-x

31 Xu L, Luo H, Wang R, Wu WW, Phue JN, Shen RF, Juhl H, Wu L, Alterovitz WL, Simonyan V, Pelosof L and Rosenberg AS: Novel reference genes in colorectal cancer identify a distinct subset of high stage tumors and their associated histologically normal colonic tissues. BMC Med Genet 20(1): 138, 2019. PMID: 31409279. DOI: 10.1186/s12881-019-0867-y

32 Koressaar T and Remm M: Enhancements and modifications of primer design program Primer3. Bioinformatics 23(10): 12891291, 2007. PMID: 17379693. DOI: 10.1093/bioinformatics/ btm091

33 Untergasser A, Cutcutache I, Koressaar T, Ye J, Faircloth BC, Remm $M$ and Rozen SG: Primer3-new capabilities and interfaces. Nucleic Acids Res 40(15): e115, 2012. PMID: 22730293. DOI: $10.1093 /$ nar/gks596

34 Altschul SF, Gish W, Miller W, Myers EW and Lipman DJ: Basic local alignment search tool. J Mol Biol 215(3): 403-410, 1990. PMID: 2231712. DOI: 10.1016/S0022-2836(05)80360-2

35 Pitule P, Vycital O, Bruha J, Novak P, Hosek P, Treska V, Hlavata I, Soucek P, Kralickova M and Liska V: Differential expression and prognostic role of selected genes in colorectal 
cancer patients. Anticancer Res 33(11): 4855-4865, 2013. PMID: 24222123.

36 Livak KJ and Schmittgen TD: Analysis of relative gene expression data using real-time quantitative PCR and the 2(Delta Delta C(T)) Method. Methods 25(4): 402-408, 2001. PMID: 11846609. DOI: 10.1006/meth.2001.1262

37 Gabut M, Samavarchi-Tehrani P, Wang X, Slobodeniuc V, O'Hanlon D, Sung HK, Alvarez M, Talukder S, Pan Q, Mazzoni EO, Nedelec S, Wichterle H, Woltjen K, Hughes TR, Zandstra PW, Nagy A, Wrana JL and Blencowe BJ: An alternative splicing switch regulates embryonic stem cell pluripotency and reprogramming. Cell 147(1): 132-146, 2011. PMID: 21924763. DOI: $10.1016 /$ j.cell.2011.08.023

38 Prochazka L, Tesarik R and Turanek J: Regulation of alternative splicing of CD44 in cancer. Cell Signal 26(10): 2234-2239, 2014. PMID: 25025570. DOI: 10.1016/j.cellsig.2014.07.011

39 Fish L, Pencheva N, Goodarzi H, Tran H, Yoshida $M$ and Tavazoie SF: Muscleblind-like 1 suppresses breast cancer metastatic colonization and stabilizes metastasis suppressor transcripts. Genes Dev 30(4): 386-398, 2016. PMID: 26883358. DOI: $10.1101 / \mathrm{gad} .270645 .115$

40 Tang L, Zhao P and Kong D: Muscleblind-like 1 destabilizes Snail mRNA and suppresses the metastasis of colorectal cancer cells via the Snail/E-cadherin axis. Int J Oncol 54(3): 955-965, 2019. PMID: 30664186. DOI: 10.3892/ijo.2019.4691

41 Fischer S, Di Liddo A, Taylor K, Gerhardus JS, Sobczak K, Zarnack K and Weigand JE: Muscleblind-like 2 controls the hypoxia response of cancer cells. RNA 26(5): 648-663, 2020. PMID: 32127384. DOI: 10.1261/rna.073353.119

42 Tabaglio T, Low DH, Teo WKL, Goy PA, Cywoniuk P, Wollmann H, Ho J, Tan D, Aw J, Pavesi A, Sobczak K, Wee DKB and Guccione E: MBNL1 alternative splicing isoforms play opposing roles in cancer. Life Sci Alliance 1(5): e201800157, 2018. PMID: 30456384. DOI: 10.26508/lsa. 201800157

43 De Smedt L, Palmans S, Govaere O, Moisse M, Boeckx B, De Hertogh G, Prenen H, Van Cutsem E, Tejpar S, Tousseyn T and Sagaert X: Expression of FOXP1 and colorectal cancer prognosis. Lab Med 46(4): 299-311, 2015. PMID: 26489674. DOI: 10.1309/LM7IHV2NJI1PHMXC

44 Feng J, Zhang X, Zhu H, Wang X, Ni S and Huang J: High expression of FoxP1 is associated with improved survival in patients with non-small cell lung cancer. Am J Clin Pathol 138(2): 230-235, 2012. PMID: 22904134. DOI: 10.1309/ AJCPDHQFNYJZ01YG

45 Pitule P, Cedikova M, Daum O, Vojtisek J, Vycital O, Hosek P, Treska V, Hes O, Kralickova M and Liska V: Immunohistochemical detection of cancer stem cell related markers CD44 and CD133 in metastatic colorectal cancer patients. Biomed Res Int 2014: 432139, 2014. PMID: 24864242 . DOI: $10.1155 / 2014 / 432139$

46 Wang Z, Tang Y, Xie L, Huang A, Xue C, Gu Z, Wang K and Zong S: The prognostic and clinical value of CD44 in colorectal cancer: A meta-analysis. Front Oncol 9: 309, 2019. PMID: 31114754. DOI: 10.3389/fonc.2019.00309
47 Todaro M, Gaggianesi M, Catalano V, Benfante A, Iovino F, Biffoni M, Apuzzo T, Sperduti I, Volpe S, Cocorullo G, Gulotta G, Dieli F, De Maria R and Stassi G: CD44v6 is a marker of constitutive and reprogrammed cancer stem cells driving colon cancer metastasis. Cell Stem Cell 14(3): 342-356, 2014. PMID: 24607406. DOI: 10.1016/j.stem.2014.01.009

48 Kim YD, Kim HS, Lee J, Choi JK, Han E, Jeong JE and Cho YS: ESRP1-induced CD44 v3 is important for controlling pluripotency in human pluripotent stem cells. Stem Cells 36(10): 1525-1534, 2018. PMID: 29873154. DOI: 10.1002/stem.2864

49 Kuniyasu H, Oue N, Tsutsumi M, Tahara E and Yasui W: Heparan sulfate enhances invasion by human colon carcinoma cell lines through expression of CD44 variant exon 3. Clin Cancer Res 7(12): 4067-4072, 2001. PMID: 11751503.

50 Toden S, Kunitoshi S, Cardenas J, Gu J, Hutchins E, Van Keuren-Jensen K, Uetake H, Toiyama Y and Goel A: Cancer stem cell-associated miRNAs serve as prognostic biomarkers in colorectal cancer. JCI Insight 4(6): 2019. PMID: 30895943. DOI: $10.1172 /$ jci.insight.125294

51 Ropponen KM, Eskelinen MJ, Lipponen PK, Alhava E and Kosma VM: Expression of CD44 and variant proteins in human colorectal cancer and its relevance for prognosis. Scand J Gastroenterol 33(3): 301-309, 1998. PMID: 9548625. DOI: 10.1080/00365529850170900

$52 \mathrm{Ma} \mathrm{L}$, Dong L and Chang P: CD44v6 engages in colorectal cancer progression. Cell Death Dis 10(1): 30, 2019. PMID: 30631039. DOI: 10.1038/s41419-018-1265-7

53 Wang Z, Zhao K, Hackert T and Zöller M: CD44/CD44v6 a reliable companion in cancer-initiating cell maintenance and tumor progression. Front Cell Dev Biol 6: 97, 2018. PMID: 30211160. DOI: 10.3389/fcell.2018.00097

54 Parra M, Gee S, Chan N, Ryaboy D, Dubchak I, Mohandas N, Gascard PD and Conboy JG: Differential domain evolution and complex RNA processing in a family of paralogous EPB41 (protein 4.1) genes facilitate expression of diverse tissue-specific isoforms. Genomics 84(4): 637-646, 2004. PMID: 15475241. DOI: $10.1016 /$ j.ygeno.2004.06.004

55 Baines AJ, Lu HC and Bennett PM: The protein 4.1 family: Hub proteins in animals for organizing membrane proteins. Biochim Biophys Acta 1838(2): 605-619, 2014. PMID: 23747363. DOI: 10.1016/j.bbamem.2013.05.030
Received February 14, 2021

Revised March 22, 2021

Accepted March 29, 2021 